\title{
Pengaruh Store Atmosphere, Hedonic Shopping, Dan Promosi Terhadap Impulsive Buying
}

\author{
Rindyah Hanafi ${ }^{1}$, Indra Tri Hutomo ${ }^{2}$ \\ ${ }^{1}$ Fakultas Ekonomi, Universitas Merdeka Madiun, Jl.Serayu 79, Madiun, 63133 \\ E-mail: rindyahanafi@unmer-madiun.ac.id \\ ${ }^{2}$ Fakultas Ekonomi, Universitas Merdeka Madiun, Jl.Serayu 79, Madiun, 63133 \\ E-mail: indra.winiarta@gmail.com
}

\begin{abstract}
This study aims to determine the influence of store atmosphere, hedonic shopping, and partial and simultaneous promotion of impulsive buying conducted in the modern retail community in Madiun City. The population in this study is the consumers of various selected big retails in Madiun City, namely Matahari Department Store Madiun Plaza and Sun City Mall, Carrefour, Ramayana and Samudra Swalayan. In this study, the number of population is not known with certainty, so in this study the number of samples used is determined based on the model estimation interval model for the parameter of proportion $P$, so that the sample obtained as many as $\mathbf{1 0 0}$ people. The sampling technique used in this research is by using purposive convenience sampling technique. Data analysis techniques use classical assumption test, multiple linear regression analysis, coefficient of determination test, and hypothesis testing by using $t$ test and $F$ test. The findings were obtained: (1) Store atmosphere partially influence to impulsive buying done by society in modern retail in Madiun City. (2) Hedonic shopping partially affects the impulsive buying done by society in modern retail in Madiun City. (3) Promotion partially influence to impulsive buying done by society in modern retail in Madiun City. (4) Store atmosphere, hedonic shopping, and promotion simultaneously affect the impulsive buying done in the modern retail community in Madiun City.
\end{abstract}

Keywords—: Store Atmosphere; Hedonic Shopping; Promotion; Impulsive Buying.

\section{PENDAHULUAN}

Persaingan bisnis ritel di Indonesia semakin kompetitif, Peritel yang masih mengelola secara tradisional harus ikut membenahi diri menjadi bisnis ritel modern jika tidak ingin terpuruk. Di Indonesia kini bisnis ritel modern semakin banyak bermunculan bahkan di kota-kota kecil dan menengah. Bagi peritel bisnis ini merupakan usaha yang menarik dan mempunyai tantangan besar karena berhubungan langsung dengan konsumen yang mempunyai latar belakang berbeda-beda..

Ada berbagai bentuk ritel modern seperti minimarket, supermarket, department store, shopping center, mall, plaza dan hypermarket. Bisnis ritel merupakan semua kegiatan penjualan barang dan jasa secara langsung kepada konsumen akhir untuk pemakaian pribadi dan rumah tangga, bukan untuk keperluan bisnis (Tjiptono, 2008: 191, Levy and Weist 2009). Indonesia mempunyai daya tarik bagi para peritel karena jumlah penduduknya sangat besar karena mereka akan lebih banyak mengkonsumsi dibandingkan dengan negara lain yang mempunyai jumlah penduduk sedikit.

Pada perkembangannya meskipun jumlah konsumen besar Peritel di Indonesia mengharapkan adanya pertumbuhan konsumsi barang ritel akan tetapi hal tersebut sangat sulit akibat terdampak dari revolusi industry 4.0. Pada sebagian besar genersi muda yang sering disebut dengan generasi milenial dalam masyarakat, mengalami perubahan pola konsumsi dan belanja. Kaum muda ini lebih suka berberbelanja melalui $e$-commerce.

Kini berbagai kota di Indonesia baik kota kecil, menengah atau besar sangat banyak usaha ritel, demikian juga didi kota Madiun juga bermunculan ritel modern ukuran besar, menengah maupun kecil seperti Matahari Department Store, Hypermart, Carrefour, Ramayana dan Samudra Swalayan, Familindo, Alfamart dan lain-lain. Perkembangan bisnis ritel modern di Kota Madiun, tidak terlepas dari karakter unik yang dimiliki oleh konsumen Indonesia. Karakter unik dalam hal ini adalah perilaku konsumen yang memiliki ciri khas tersendiri dibandingkan dengan sebagian besar konsumen lain. Menurut Irawan (dalam Fahd dan Sugiarto, 2015: 1) konsumen Indonesia memiliki sepuluh karakter unik, yaitu berpikir jangka pendek, tidak terencana, gagap teknologi, orientasi pada konteks, suka merek luar negeri, religius, gengsi, kuat disubkultur, kurang peduli lingkungan dan suka bersosialisasi. Menurut Susanta (dalam Sari, 2014: 56) "sebagian besar konsumen Indonesia memiliki karakter unplanned. Mereka biasanya suka bertindak last minute. Jika berbelanja, mereka sering menjadi impulse buyer." Sehubungan dengan itu, maka perilaku pembelian yang tidak direncanakan atau impulse buying (pembelian impulsif) merupakan sesuatu yang menarik bagi produsen maupun pengecer, karena merupakan pangsa pasar terbesar dalam pasar modern. Impulse buying atau biasa disebut juga unplanned purchase, adalah perilaku orang dimana orang tersebut tidak merencanakan sesuatu dalam berbelanja. Menurut Mowen \& Minor (2010: 10) definisi impulse buying adalah tindakan membeli yang dilakukan tanpa memiliki masalah sebelumnya atau maksud/niat membeli yang terbentuk sebelum memasuki toko. Impulse buying merupakan keputusan yang emosional atau menurut desakan hati. 
Fenomena impulsive buying dapat terjadi pada semua kalangan masyarakat, termasuk masyarakat Kota Madiun yang masyarakatnya berdaya beli kuat, di mana jumlah penduduk Kota Madiun yang padat dengan pertumbuhan ekonomi yang semakin meningkat, disertai pendapatan masyarakat yang memadai dan bermunculan banyak industri membuat perilaku belanja masyarakat menjadi semakin meningkat. Tentang perilaku belanja masyarakat Kota Madiun yang semakin meningkat, di mana saat mereka melakukan kegiatan berbelanja, mereka membuat keputusan pembelian ketika sedang berada di dalam gerai atau cenderung melakukan pembelian secara mendadak. Misalnya, ketika sedang jalan-jalan di mall, seseorang melihat ada pakaian model baru yang terpajang dengan harga diskon yang besar, akhirnya memutuskan membeli meskipun ketika berangkat dari rumah tidak ada rencana untuk membeli pakaian. Hal ini menunjukkan bahwa kondisi mall maupun program promosi melalui pemberian diskon mampu mempengaruhi psikologis konsumen.

Impulsive buying atau pembelian impulsif merupakan sebuah fenomena dan kecenderungan perilaku berbelanja meluas yang terjadi di dalam pasar sehingga menjadi poin penting dalam pemasaran. Pembelian impulsif merupakan aspek penting dalam perilaku konsumen dan konsep yang vital bagi peritel sebab pembelian tidak terencana yang dilakukan oleh konsumen secara langsung akan berkontribusi pada nilai omset penjualan yang didapat oleh peritel tersebut (Abdolvand, Hanzaee, Rahmana, dan Koshpanjeh, 2011: 4). Seringkali keputusan pembelian diambil oleh konsumen merupakan pembelian tanpa rencana sebelumnya, dimana pembelian tersebut dilakukan secara spontan, karena konsumen tertarik dengan adanya diskon, suasana hati yang positif maupun karena adanya stimulus dari lingkungan toko yang menarik, sehingga menimbulkan minat konsumen untuk membeli. Mengingat besarnya pengaruh impulsive buying terhadap total penjualan, maka pemasar perlu untuk mengidentifikasi faktor-faktor penyebabnya untuk dapat memformulasikan strategi pemasaran yang tepat.

Impulsive buying dapat ditimbulkan akibat adanya rangsangan dari lingkungan toko (Utami, 2010: 50). Kunci dalam menarik dan membuat konsumen terkesan dengan kegiatan berbelanja di dalam ritel adalah store atmosphere atau atmosfir toko. Hasil penelitian yang dilakukan Pamayun dan Ekawati (2016: 4156) menemukan bahwa atmosfer gerai berpengaruh positif dan signifikan terhadap pembelian impulsif. Store atmosphere yang dirasakan oleh pelanggan sangat mempengaruhi emosi mereka dalam berbelanja sehingga pelanggan menjadi nyaman dan dapat berlama-lama di dalam toko. Ketika pelanggan merasakan suasana yang baik, maka secara tidak langsung emosi positif yang dimiliki pengunjung juga ikut meningkat, sehingga mengakibatkan pengunjung merasa senang dan ingin berbelanja yang di luar daftar keperluannya.

Store atmosphere harus diperhatikan para pelaku usaha ritel agar konsumen bisa melakukan kegiatan berbelanja dengan nyaman. Menurut Coley dan Burgess dalam Yistiani, Yasa, dan Suasana (2012: 140) store atmosphere merupakan "salah satu elemen bauran pemasaran ritel yang terkait dalam hal penciptaan suasana belanja. Atmosfer merupakan kunci dalam menarik dan membuat konsumen terkesan dengan pengalaman berbelanja di dalam gerai." Dalam bisnis yang kompetitif saat ini, atmosfer gerai dianggap sebagai salah satu hal yang penting bagi toko ritel. Lingkungan berbelanja dapat didesain sedemikian rupa dengan tujuan menimbulkan efek emosional dalam diri konsumen, sehingga meningkatkan kemungkinan terjadinya pembelian. Atmosfer dalam gerai merupakan hal yang perlu diperhatikan bagi pelaku bisnis ritel untuk membuat konsumen nyaman melakukan kegiatan berbelanja di dalam gerai.

Fenomena yang ditemukan pada masyarakat di Kota Madiun bahwa kebanyakan masyarakat lebih berorientasi rekreasi saat berbelanja. Ini sama halnya dengan konsumen lebih mementingkan nilai hedonik saat berbelanja yaitu rasa senang dan bahagia dari pengalaman belanja. Hedonik merupakan stimuli yang menseleksi kualitas lingkungan belanja dari sisi kenikmatan (enjoyment) yang dirasakan, rasa tertarik akibat pandangan mata (visual appeal) dan rasa lega (escapism) (Subagio, 2011: 15). Hedonic shopping value menurut Usvita (2016: 71-75) memainkan peran penting dalam impulse buying. Oleh karena itu, seringkali konsumen mengalami impulse buying ketika didorong oleh keinginan hedonis atau sebab lain di luar alasan ekonomi, seperti karena rasa suka terhadap produk, senang, sosial, atau pengaruh emosional. Nilai belanja hedonik mencerminkan instrumen yang menyajikan secara langsung manfaat dari suatu pengalaman dalam melakukan pembelanjaan, seperti: kesenangan dan hal-hal baru. Konsumsi hedonis meliputi aspek tingkah laku yang berhubungan dengan multi-sensory, fantasi dan konsumsi emosional yang dikendalikan oleh manfaat seperti kesenangan dalam menggunakan produk dan pendekatan estetis.

Menurut Japarianto (2010: 77) berbagai pusat perbelanjaan sengaja menciptakan suasana yang hedonis. Penciptaan suasana hedonis ini dimaksudkan untuk menarik pengunjung dan membuat mereka puas sehingga betah berlama-lama di pusat perbelanjaan dan dapat membelanjakan uangnya sehingga besar kemungkinan munculnya fenomena impulse buying. Kebiasaan orang yang lebih memilih menghabiskan waktu luangnya di pusat perbelanjaan, akan memicu terjadinya belanja hedonik. Menurut Crowley, et. al. (dalam Irani, 2011: 90) menyatakan bahwa fashion, khususnya pakaian telah diklasifikasikan sebagai produk dengan nilai hedonik tertinggi karena sifatnya yang simbolis, memiliki pengalaman, dan merupakan hal yang menyenangkan. Pengetahuan akan perilaku konsumen harus dipahami dengan benar oleh peritel sehingga diharapkan gerai fashion mampu melakukan pendekatan yang tepat bagi konsumen maupun calon konsumen yang datang sehingga diharapkan akan terjadi tindak lanjut berupa pembelian produk fashion dan dapat memotivasi terjadinya fenomena impulse buying dari tenant (gerai) tersebut. Beberapa penelitian seperti yang dilakukan oleh Prastia (2013: 72) menunjukkan bahwa nilai belanja hedonik berpengaruh terhadap impulse buying. Hal ini sesuai dengan penelitian yang dilakukan oleh Foroughi, Buang, Senik, dan Hajmisadeghi (2013: 760) yaitu ada hubungan positif dan langsung antara nilai belanja hedonik dengan impulse buying. Pada penelitian yang dilakukan oleh Kosyu, Hidayat, dan Abdillah (2014: 7) menyatakan bahwa hedonic shopping motives berpengaruh signifikan terhadap impulse buying. 
Website : http://ekomaks.unmermadiun.ac.id/index.php/ekomaks

Selain store atmosphere dan nilai hedonis dalam berbelanja atau hedonic shopping value, perilaku impulsive buying pada konsumen juga dapat disebabkan strategi promosi yang disampaikan peritel. "Promosi adalah bentuk komunikasi dari penyedia produk (barang atau jasa) terhadap konsumen yang bertujuan untuk mendidik dan menarik konsumen terhadap produk yang ditawarkan" (Smith, 2008: 170). Promosi melibatkan semua bentuk komunikasi dengan konsumen, bukan hanya iklan. Tidak jarang peritel memberikan potongan harga, hadiah-hadiah (gifts), undian berhadiah, lomba (dikaitkan dengan belanja), program pelanggan setia, penawaran produk-produk dan banyak lainnya untuk menarik perhatian para konsumennya. Hasil penelitian yang dilakukan Leba dan Suhermin (2015: 13) menemukan bahwa variabel promosi memiliki pengaruh positif dan signifikan terhadap variabel pembelian impulsif. Hal ini menunjukkan semakin baik kegiatan promosi yang dilakukan maka akan meningkatkan pembelian impulsif pada konsumen.

Promosi merupakan kegiatan yang dilakukan perusahaan untuk meningkatkan ataupun memperkenalkan adanya suatu produk yang dijual suatu perusahaan yang bertujuan untuk mendorong kegiatan pembelian bagi para pelanggannya. Seperti yang diungkapkan oleh Peter dan Olson (2014: 204) promosi dirasakan konsumen sebagai aspek sosial dan fisik dari lingkungan yang dapat mempengaruhi tanggapan afeksi dan kognisi konsumen. Tujuan dari promosi tersebut adalah memberikan rangsangan kepada konsumen yang awalnya tidak ingin membeli menjadi ingin membeli. Program promosi yang disampaikan peritel dapat berupa potongan tunai dan free product. Berdasarkan uraian di atas, terdapat beberapa faktor yang dapat mempengaruhi konsumen untuk melakukan pembelian impulsif di berbagai gerai ritel modern. Faktor-faktor tersebut di antaranya adalah store atmosphere, hedonic shopping, dan promosi.

Berdasarkan uraian latar belakang masalah di atas, maka dapat disusun rumusan masalah sebagai berikut:

1. Apakah store atmosphere berpengaruh terhadap impulsive buying yang dilakukan masyarakat di ritel-ritel modern yang ada di Kota Madiun?

2. Apakah hedonic shopping berpengaruh terhadap impulsive buying yang dilakukan masyarakat di ritel-ritel modern yang ada di Kota Madiun?

3. Apakah promosi berpengaruh terhadap impulsive buying yang dilakukan masyarakat di ritel-ritel modern yang ada di Kota Madiun?

4. Apakah store atmosphere, hedonic shopping, dan promosi berpengaruh simultan terhadap impulsive buying yang dilakukan masyarakat di ritel-ritel modern yang ada di Kota Madiun?

\section{METODE PENELITIAN}

Penelitian ini merupakan penelitian asosiatif kausal (causal research), yaitu mengidentifikasikan hubungan sebab-akibat antara variabel-variabel pembentuk model dengan menggunakan pendekatan kuantitatif. Penelitian ini dikategorikan sebagai penelitian kuantitatif (quantitative research). Penelitian kuantitatif dapat diartikan sebagai metode penelitian yang berlandaskan pada filsafat positivisme, digunakan untuk meneliti pada populasi atau sampel tertentu, pengumpulan data menggunakan instrumen penelitian, analisis data bersifat kuantitatif/statistik, dengan tujuan untuk menguji hipotesis yang telah ditetapkan (Sugiyono, 2012: 14). Penelitian kuantitatif menyederhanakan kompleksitas gejala dengan mereduksi ke dalam ukuran yang dapat ditangani dan diukur. Ukuran dari gejala yang

dapat ditangani dan diukur itu dikenal sebagai variabel. Penyederhanaan dilakukan agar penelitian membatasi pada ukuran yang membuka kesempatan pada orang lain untuk melakukan pengujian kembali terhadap kebenaran hasil penelitian. Dalam penelitian kuantitatif, variabel, dan hubungannya nampak dari rumusan masalahnya (Purwanto, 2007: 134).

Populasi dalam penelitian ini adalah konsumen yang pernah berbelanja di berbagai ritel besar terpilih yang ada di Kota Madiun, yaitu Matahari Departmen Store Jalan Pahlawan dan Sun City Mall, Ramayana Lawu Plaza, Carrefour, dan Samudra Swalayan. Oleh karena jumlah populasi tidak diketahui dengan pasti, maka dalam penelitian ini jumlah sampel yang digunakan ditentukan berdasarkan rumus model interval taksiran untuk parameter proporsi $\mathrm{P}$ sebagai berikut $($ Umar, 2011:109): $\mathrm{n}=$ $\mathrm{pq}\left(\mathrm{Z}_{\alpha / 2} / \mathrm{e}\right)^{2}, \mathrm{n}=$ ukuran sampel, $\mathrm{e}=$ kelonggaran ketidaktelitian karena kesalahan pengambilan sampel yang tidak ditolerir, $\mathrm{p}=$ parameter proporsi $\mathrm{p}$; sedangkan $\mathrm{q}=1$-p. Jika $\mathrm{p}$ dan $\mathrm{q}$ tidak diketahui, maka dapat diganti dengan 0,25 sebagai perkalian antara 0,5 x 0,5. (Umar, 2011:109). Pada penelitian ini besarnya kesalahan error (e) adalah sebanyak 10\% dengan $\alpha$ sebesar 0,05 $(Z=1,96)$ dan nilai p.q sebesar 0,25 , maka besarnya sampel yang akan digunakan adalah: $\mathrm{n}=0,25(1,96 / 0,1)^{2}=96,04 \approx 100$ sampel.

Teknik sampling yang digunakan dalam penelitian ini adalah purposive convenience sampling. Menurut Sugiyono (2015:120), yaitu "metode pemilihan sampel yang dilakukan secara tidak acak dengan menggunakan pertimbangan tertentu (purposive) dan berdasarkan kemudahan (convenience)." Berdasarkan hal tersebut maka dalam penelitian ini diperoleh sampel sebanyak 100 orang warga kota Madiun yang melakukan pembelian di berbagai ritel besar terpilih yang ada di Kota Madiun, yaitu: Matahari Departmen Store Jalan Pahlawan dan Sun City Mall, Carrefour, Ramayana Lawu Plaza dan Samudra Swalayan.

Jenis data yang digunakan dalam penelitian ini ada 2 macam, yaitu: (1) Data primer, adalah data yang langsung diperoleh dari sumber data untuk tujuan khusus. Data primer yang dibutuhkan dalam penelitian ini meliputi: karakteristik respoden, serta persepsi responden tentang store atmosphere, hedonic shopping, promosi, dan impulsive buying. Data primer dikumpulkan melalui kuesioner yang dibagikan kepada responden. (2) Data sekunder, merupakan data yang telah lebih dahulu dikumpulkan dan dilaporkan oleh pihak lain sebagai pemberi informasi diluar peneliti. Data sekunder dalam penelitian ini meliputi profil perusahaan dan data-data lain yang menunjang, seperti teori-teori tentang store atmosphere, hedonic shopping, promosi, dan 
impulsive buying. Data sekunder yang digunakan dalam penelitian ini diperoleh dari berbagai sumber, yaitu: jurnal, artikel, dan buku-buku referensi.

Untuk menguji kecukupan sampel dan instrumen kuesioner digunakan uji validitas dan reliabititas, kemudian data yang terkumpul melalui hasil penyebaran kuesioner diseleksi dan diedit menurut kebutuhan kemudian dihitung statistik dengan menggunakan program SPSS untuk pengujian: Uji asumsi klasik meliputi beberapa uji, yaitu uji multikolinearitas, uji heteroskedastisitas, dan uji normalitas. Analisis regresi linear berganda digunakan untuk mengetahui hubungan antara variabel bebas dengan variabel terikat, yaitu antara store atmosphere $\left(\mathrm{X}_{1}\right)$, hedonic shopping $\left(\mathrm{X}_{2}\right)$, dan promosi $\left(\mathrm{X}_{3}\right)$ terhadap impulsive buying (Y). Adapun persamaan regresi yang digunakan adalah sebagai berikut: $\mathrm{Y}=\mathrm{a}+\mathrm{b}_{1} \mathrm{X}_{1}+\mathrm{b}_{2} \mathrm{X}_{2}+\mathrm{b}_{3} \mathrm{X}_{3}+\mathrm{e}$

Notasi dari model tersebut adalah:

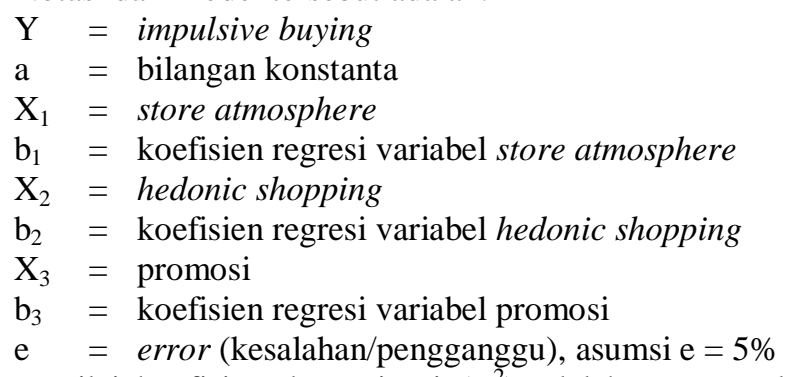

Nilai koefisien determinasi $\left(\mathrm{R}^{2}\right)$ adalah antara nol dan satu. Nilai koefisien determinasi yang kecil berarti kemampuan variabel-variabel bebas dalam menjelaskan variasi variabel terikat amat terbatas. Penentuan nilai koefisien determinasi dinyatakan dengan nilai Adjusted $R$ Square. Uji Statistik dengan menggunakan Uji t (Uji parsial) dan uji F. Uji t digunakan untuk menguji pengaruh variabel independen, yaitu store atmosphere, hedonic shopping, dan promosi secara parsial terhadap impulsive buying sebagai variabel dependen. Uji F digunakan untuk mengetahui pengaruh seluruh variabel independen secara serentak atau simultan terhadap variabel dependen.

\section{III.HASIL DAN PEMBAHASAN}

Responden penelitian ini sebanyak 100 orang konsumen dari Matahari Departmen Store Plaza Madiun dan Sun City Mall, Carrefour, Ramayana dan Samudra Swalayan, yang dipilih dengan teknik purposive convenience sampling. Kecukupan sampel di uji menggunakan Uji validitas, uji tersebut dilakukan dengan membandingkan nilai $r_{\text {hitung }}$ dengan nilai $r_{\text {tabel }}$. Jika $r_{\text {hitung }}$ (untuk $r$ tiap butir dapat dilihat pada kolom Corrected Item-Total Correlation) lebih besar dari $r_{\text {tabel }}$ dan nilai $r$ positif, maka butir atau pernyataan atau indikator tersebut dikatakan valid. Taraf signifikansi ( $\alpha$ ) yang digunakan adalah 0,05 atau 5\%. Pada penelitian ini, uji validitas instrumen disampaikan kepada 100 orang responden. Dengan demikian, nilai $\mathrm{n}=100$. Nilai $\mathrm{r}$ tabel dengan $(\alpha)$ $5 \%$ dan $\mathrm{df}=\mathrm{n}-2=98$ adalah sebesar 0,1966.

Berdasarkan hasil pengolahan data dengan program SPSS maka diperoleh nilai $\mathrm{r}_{\text {hitung }}$ (Corrected Item - Total Correlation) untuk variabel store atmosphere sebagai berikut

\begin{tabular}{|c|c|c|c|}
\hline $\begin{array}{c}\text { Item } \\
\text { Variabel }\end{array}$ & $\begin{array}{l}\text { Nilai } \\
\mathbf{r}_{\text {hitung }}\end{array}$ & $\begin{array}{l}\text { Nilai } r_{\text {tabel }} \\
=0,1966\end{array}$ & $\begin{array}{c}\text { Keteanga } \\
\text { n. }\end{array}$ \\
\hline $\mathrm{X}_{1} .1$ & 0,481 & $r_{\text {hitung }}>r_{\text {table }}$ & Valid \\
\hline $\mathrm{X}_{1} .2$ & 0,540 & $r_{\text {hitung }}>r_{\text {table }}$ & Valid \\
\hline $\mathrm{X}_{1} .3$ & 0,530 & $r_{\text {hitung }}>r_{\text {table }}$ & Valid \\
\hline$X_{1} .4$ & 0,435 & $r_{\text {hitung }}>r_{\text {table }}$ & Valid \\
\hline$X_{1} .5$ & 0,553 & $r_{\text {hitung }}>r_{\text {table }}$ & Valid \\
\hline$X_{1} .6$ & 0,277 & $r_{\text {hitung }}>r_{\text {table }}$ & Valid \\
\hline $\mathrm{X}_{1} .7$ & 0,494 & $r_{\text {hitung }}>r_{\text {table }}$ & Valid \\
\hline $\mathrm{X}_{1} .8$ & 0,384 & $r_{\text {hitung }}>r_{\text {table }}$ & Valid \\
\hline $\mathrm{X}_{1} .9$ & 0,462 & $r_{\text {hitung }}>r_{\text {table }}$ & Valid \\
\hline $\mathrm{X}_{1} .10$ & 0,581 & $r_{\text {hitung }}>r_{\text {table }}$ & Valid \\
\hline $\mathrm{X}_{1} .11$ & 0,554 & $r_{\text {hitung }}>r_{\text {table }}$ & Valid \\
\hline $\mathrm{X}_{1} .12$ & 0,520 & $r_{\text {hitung }}>r_{\text {table }}$ & Valid \\
\hline
\end{tabular}

Dari nilai $\mathrm{r}_{\text {hitung }}$ yang diperoleh dapat diketahui bahwa keseluruhan butir pernyataan untuk variabel store atmosphere, yaitu item store atmosphere 1 sampai item store atmosphere 12 memiliki nilai $r_{\text {hitung }}$ yang lebih besar daripada nilai $r_{\text {tabel }}(0,1966)$, maka semua butir pernyataan yang digunakan memenuhi syarat validitas.

Hasil pengolahan data dengan program SPSS maka diperoleh nilai $\mathrm{r}_{\text {hitung }}$ untuk variabel hedonic shopping sebagai berikut:

\begin{tabular}{cccc}
\multicolumn{4}{c}{ Tabel 2. Uji Validitas Variabel Hedonic Shopping $\left(\mathrm{X}_{2}\right)$} \\
\hline Item & Nilai & Nilai $\mathbf{r}_{\text {tabel }}$ & Ket. \\
Variabel & $\mathbf{r}_{\text {hitung }}$ & $\mathbf{0 , 1 9 6 6}$ & \\
\hline $\mathrm{X}_{2} \cdot 1$ & 0,466 & $\mathrm{r}_{\text {hitung }}>\mathrm{r}_{\text {table }}$ & Valid \\
$\mathrm{X}_{2} \cdot 2$ & 0,418 & $\mathrm{r}_{\text {hitung }}>\mathrm{r}_{\text {table }}$ & Valid
\end{tabular}


Website : http://ekomaks.unmermadiun.ac.id/index.php/ekomaks

\begin{tabular}{cccc}
\hline $\begin{array}{c}\text { Item } \\
\text { Variabel }\end{array}$ & $\begin{array}{c}\text { Nilai } \\
\mathbf{r}_{\text {hitung }}\end{array}$ & $\begin{array}{c}\text { Nilai } \mathbf{r}_{\text {tabel }} \\
=\mathbf{0 , 1 9 6 6}\end{array}$ & Ket. \\
\hline $\mathrm{X}_{2} .3$ & 0,635 & $\mathrm{r}_{\text {hitung }}>\mathrm{r}_{\text {table }}$ & Valid \\
$\mathrm{X}_{2} \cdot 4$ & 0,584 & $\mathrm{r}_{\text {hitung }}>\mathrm{r}_{\text {table }}$ & Valid \\
$\mathrm{X}_{2} .5$ & 0,544 & $\mathrm{r}_{\text {hitung }}>\mathrm{r}_{\text {table }}$ & Valid \\
$\mathrm{X}_{2} \cdot 6$ & 0,582 & $\mathrm{r}_{\text {hitung }}>\mathrm{r}_{\text {table }}$ & Valid \\
$\mathrm{X}_{2} .7$ & 0,587 & $\mathrm{r}_{\text {hitung }}>\mathrm{r}_{\text {table }}$ & Valid \\
$\mathrm{X}_{2} .8$ & 0,596 & $\mathrm{r}_{\text {hitung }}>\mathrm{r}_{\text {table }}$ & Valid \\
$\mathrm{X}_{2} .9$ & 0,519 & $\mathrm{r}_{\text {hitung }}>\mathrm{r}_{\text {table }}$ & Valid \\
$\mathrm{X}_{2} .10$ & 0,503 & $\mathrm{r}_{\text {hitung }}>\mathrm{r}_{\text {table }}$ & Valid \\
\hline \multicolumn{5}{c}{}
\end{tabular}

Nilai $\mathrm{r}_{\text {hitung }}$ dari item hedonic shopping 1 sampai item hedonic shopping 10 memiliki nilai $\mathrm{r}_{\text {hitung }}$ yang lebih besar daripada nilai $r_{\text {tabel }}(0,1966)$, maka semua butir pernyataan valid.

Nilai $r_{\text {hitung }}$ untuk variabel promosi sebagai berikut:

\begin{tabular}{cccc}
\multicolumn{4}{c}{ Tabel 3. Uji Validitas Variabel Promosi $\left(\mathrm{X}_{3}\right)$} \\
$\begin{array}{c}\text { Item } \\
\text { Variabel }\end{array}$ & $\begin{array}{c}\text { Nilai } \\
\mathbf{r}_{\text {hitung }}\end{array}$ & $\begin{array}{c}\text { Nilai } \mathbf{r}_{\text {tabel }} \\
\mathbf{= 0 , 1 9 6 6}\end{array}$ & Ket. \\
\hline $\mathrm{X}_{3} .1$ & 0,616 & $\mathrm{r}_{\text {hitung }}>\mathrm{r}_{\text {table }}$ & Valid \\
$\mathrm{X}_{3} .2$ & 0,688 & $\mathrm{r}_{\text {hitung }}>\mathrm{r}_{\text {table }}$ & Valid \\
$\mathrm{X}_{3} \cdot 3$ & 0,646 & $\mathrm{r}_{\text {hitung }}>\mathrm{r}_{\text {table }}$ & Valid \\
$\mathrm{X}_{3} \cdot 4$ & 0,750 & $\mathrm{r}_{\text {hitung }}>\mathrm{r}_{\text {table }}$ & Valid \\
$\mathrm{X}_{3} \cdot 5$ & 0,778 & $\mathrm{r}_{\text {hitung }}>\mathrm{r}_{\text {table }}$ & Valid \\
$\mathrm{X}_{3} \cdot 6$ & 0,559 & $\mathrm{r}_{\text {hitung }}>\mathrm{r}_{\text {table }}$ & Valid \\
$\mathrm{X}_{3} \cdot 7$ & 0,318 & $\mathrm{r}_{\text {hitung }}>\mathrm{r}_{\text {table }}$ & Valid \\
$\mathrm{X}_{3} \cdot 8$ & 0,232 & $\mathrm{r}_{\text {hitung }}>\mathrm{r}_{\text {table }}$ & Valid \\
$\mathrm{X}_{3} .9$ & 0,410 & $\mathrm{r}_{\text {hitung }}>\mathrm{r}_{\text {table }}$ & Valid \\
\hline \multicolumn{5}{c}{ Sumber: Output SPSS }
\end{tabular}

Pada Tabel 3, berdasarkan dari nilai $r_{\text {hitung }}$ yang diperoleh dapat diketahui bahwa keseluruhan butir pernyataan untuk variabel promosi, yaitu item promosi 1 sampai item promosi 9 memiliki nilai $r_{\text {hitung }}$ yang lebih besar dari pada nilai $r_{\text {tabel }}(0,1966)$, maka semua butir pernyataan yang digunakan memenuhi syarat validitas.

Berdasarkan hasil pengolahan data maka diperoleh nilai $\mathrm{r}_{\text {hitung }}$ untuk variabel impulsive buying sebagai berikut:

\begin{tabular}{cccc}
\multicolumn{4}{c}{ Tabel 4. Uji Validitas Variabel Impulsive Buying (Y) } \\
\hline $\begin{array}{c}\text { Item } \\
\text { Variabel }\end{array}$ & $\begin{array}{c}\text { Nilai } \\
\mathbf{r}_{\text {hitung }}\end{array}$ & $\begin{array}{c}\text { Nilai } \mathbf{r}_{\text {tabel }} \\
=\mathbf{0 , 1 9 6 6}\end{array}$ & Ket. \\
\hline Y.1 & 0,499 & $\mathrm{r}_{\text {hitung }}>\mathrm{r}_{\text {table }}$ & Valid \\
Y.2 & 0,519 & $\mathrm{r}_{\text {hitung }}>\mathrm{r}_{\text {table }}$ & Valid \\
Y.3 & 0,542 & $\mathrm{r}_{\text {hitung }}>\mathrm{r}_{\text {table }}$ & Valid \\
Y.4 & 0,488 & $\mathrm{r}_{\text {hitung }}>\mathrm{r}_{\text {table }}$ & Valid \\
Y.5 & 0,662 & $\mathrm{r}_{\text {hitung }}>\mathrm{r}_{\text {table }}$ & Valid \\
Y.6 & 0,548 & $\mathrm{r}_{\text {hitung }}>\mathrm{r}_{\text {table }}$ & Valid \\
Y.7 & 0,625 & $\mathrm{r}_{\text {hitung }}>\mathrm{r}_{\text {table }}$ & Valid \\
Y.8 & 0,582 & $\mathrm{r}_{\text {hitung }}>\mathrm{r}_{\text {table }}$ & Valid \\
Y.9 & 0,507 & $\mathrm{r}_{\text {hitung }}>\mathrm{r}_{\text {table }}$ & Valid \\
Y.10 & 0,434 & $\mathrm{r}_{\text {hitung }}>\mathrm{r}_{\text {table }}$ & Valid \\
\hline \multicolumn{5}{c}{ Sumber: Output SPSS } &
\end{tabular}

Pada Tabel 4, nilai $\mathrm{r}_{\text {hitung }}$ dari item impulsive buying 1 sampai item impulsive buying 10 memiliki nilai $\mathrm{r}_{\text {hitung }}$ yang lebih besar daripada nilai $r_{\text {tabel }}(0,1966)$, maka semua butir pernyataan valid. Berdasarkan uji validitas yang dilakukan, dapat diketahui bahwa keseluruhan butir item/faktor untuk masing-masing variabel penelitian adalah memenuhi syarat validitas. Dengan demikian, keseluruhan butir pernyataan kuesioner ini adalah valid dan dapat digunakan untuk mengumpulkan data penelitian.

Kuesioner yang dikumpulkan dan valid untuk dianalisis, selanjutnya dilakukan pengelompokan untuk pertanyaan-pertanyaan yang diajukan dan menentukan nilai masing-masing variabel dari sejumlah pertanyaan yang digunakan untuk mengukur variabel tersebut. Sebanyak 100 kuesioner yang telah terkumpul, dilakukan pengujian reliabilitas dengan menggunakan “Cronbach's Coefficient Alpha". Suatu konstruk atau variabel dikatakan reliabel jika memberikan nilai Cronbach Alpha $(\alpha)>$ 0,70. Dengan mendasarkan pada ketentuan tersebut dapat disimpulkan bahwa uji reliabilitas untuk alat ukur memenuhi ketentuan untuk diterima. Adapun reliabilitas ini disajikan tabel berikut:

\begin{tabular}{lccc}
\multicolumn{4}{c}{ Tabel 5. Hasil Uji Reliabilitas } \\
\hline \multicolumn{1}{c}{ Variabel } & $\begin{array}{c}\text { Nilai } \\
\text { Alpha } \\
\text { Hitung }\end{array}$ & $\begin{array}{c}\text { Cronbach } \\
\text { Alpha }\end{array}$ & Ket. \\
\hline $\begin{array}{l}\text { Store atmosphere } \\
\left(\mathrm{X}_{1}\right)\end{array}$ & 0,711 & 0,70 & Reliabel \\
Hedonic shopping & 0,733 & 0,70 & Reliabel
\end{tabular}


Website : http://ekomaks.unmermadiun.ac.id/index.php/ekomaks

\begin{tabular}{lccc}
$\left(\mathrm{X}_{2}\right)$ & & \\
Promosi $\left(\mathrm{X}_{3}\right)$ & 0,718 & 0,70 & Reliabel \\
$\begin{array}{l}\text { Impulsive buying } \\
\text { (Y) }\end{array}$ & 0,719 & 0,70 & Reliabel \\
\hline \multicolumn{4}{r}{ Sumber: Output SPSS }
\end{tabular}

Berdasarkan Tabel 5, dapat disimpulkan bahwa semua variabel memiliki nilai cronbach alpha di atas 0,70 dengan demikian dapat dinyatakan bahwa instrumen masing-masing variabel adalah reliabel.

Uji Multikolinearitas

Uji multikolinieritas dapat dilihat dari nilai tolerance dan variance inflation factor (VIF). Apabila tolerance lebih dari $10 \%$ atau 0,1 dan VIF kurang dari 10 maka tidak terjadi multikolinieritas.

Tabel 6. Nilai Tolerance dan VIF

Coefficients $^{a}$

\begin{tabular}{|ll|r|r|}
\hline \multicolumn{2}{|c|}{} & \multicolumn{2}{|c|}{ Collinearity Statistics } \\
\cline { 3 - 4 } Model & Tolerance & \multicolumn{1}{l|}{ VIF } \\
\hline 1 & Store Atmosphere & .869 & 1.151 \\
& Hedonic Shopping & .869 & 1.151 \\
& Promosi & .999 & 1.001 \\
\hline
\end{tabular}

a. Dependent Variable: Impulsive Buying

Sumber: Output SPSS

Mengacu pada Tabel 6 di atas, dapat dilihat bahwa nilai Variance Influence Factor (VIF) ketiga variabel lebih kecil dari 10. Variabel store atmosphere $\left(\mathrm{X}_{1}\right)$ dan hedonic shopping $\left(\mathrm{X}_{2}\right)$ memiliki nilai $\mathrm{VIF}=1,151$, sedangkan dan variabel promosi $\left(\mathrm{X}_{3}\right)=$ 1,001. Dari ketiga variabel tersebut berarti tidak terdapat korelasi yang kuat di antara salah satu variabel bebas dengan variabel bebas lainnya. Artinya, persoalan multikolinearitas di antara semua variabel bebas masih dapat ditolerir. Sedangkan nilai tolerance variabel store atmosphere $\left(\mathrm{X}_{1}\right)$ dan hedonic shopping $\left(\mathrm{X}_{2}\right)$ adalah sebesar 0,869 , sedangkan variabel promosi $\left(\mathrm{X}_{3}\right)=$ 0,999. Nilai tolerance ketiga variabel menunjukkan lebih besar dari 0,1 . Artinya, di antara variabel bebas tidak terjadi multikolinieritas. Dengan demikian, masing-masing variabel dapat dilakukan uji regresi dengan hasil yang signifikan.

Hasil uji heteroskedastisitas menggunakan program SPSS adalah sebagai berikut:

Gambar 1.Hasil Uji Heteroskedastisitas dengan Scatterplot Scatterplot

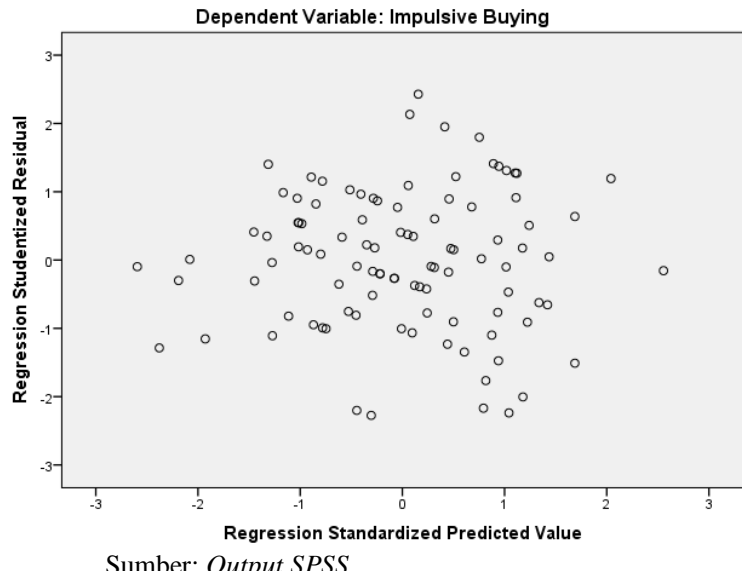

Sumber: Output SPSS

Dasar pengambilan keputusan adalah:

1) Jika ada pola tertentu, seperti titik-titik (poin-poin) yang ada membentuk suatu pola tertentu yang teratur (bergelombang, melebar, kemudian menyempit), maka telah terjadi heteroskedastisitas.

2) Jika tidak ada yang jelas, serta titik-titik menyebar di atas, dan di bawah angka nol dibawah sumbu Y, maka tidak terjadi heteroskedastisitas.

Berdasarkan Gambar 1, dapat dilihat bahwa tingkat penyebaran data dalam penelitian, menyebar di atas dan di bawah angka nol di bawah sumbu Y dan tidak membentuk pola tertentu, hal ini menunjukkan bahwa tidak terjadi heteroskedastisitas.

Uji Normalitas Data

Uji normalitas data dilakukan untuk memastikan bahwa semua data dalam penelitian ini adalah menyebar normal. Untuk menguji normalitas data ini dapat dilakukan melalui uji One Sample Kolmogorov-Smirnov yang diolah dengan program SPSS. Adapun hasil uji normalitas diperoleh hasil sebagai berikut: 
Website : http://ekomaks.unmermadiun.ac.id/index.php/ekomaks

Tabel 7. Hasil Uji Normalitas Data Menggunakan Uji One Sample Kolmogorov-Smirnov

One-Sample Kolmogorov-Smirnov Test

\begin{tabular}{|ll|r|}
\hline & & $\begin{array}{c}\text { Unstandardized } \\
\text { Residual }\end{array}$ \\
\hline $\mathrm{N}$ & Mean & 100 \\
Normal Parameters & a,b & .0000000 \\
Most Extreme Differences & Std. Deviation & .28206491 \\
& Absolute & .041 \\
Test Statistic & Positive & .040 \\
Asymp. Sig. (2-tailed) & Negative & -.041 \\
\hline
\end{tabular}

a. Test distribution is Normal.

b. Calculated from data.

c. Lilliefors Significance Correction.

d. This is a lower bound of the true significance.

Sumber: Data primer diolah

Berdasarkan hasil uji One Sample Kolmogorov-Smirnov pada Tabel 7, diperoleh nilai sig. 0,200 > 0,05, yang artinya data tersebut berdistribusi normal. Dengan demikian, data tentang store atmosphere, hedonic shopping, promosi, dan impulsive buying yang disampaikan responden penelitian terdistribusi normal.

Analisis Regresi Linier Berganda

Hasil perhitungan regresi antara variabel store atmosphere $\left(\mathrm{X}_{1}\right)$, hedonic shopping $\left(\mathrm{X}_{2}\right)$, promosi $\left(\mathrm{X}_{3}\right)$ sebagai variabel independent terhadap impulsive buying yang dilakukan konsumen pada berbagai ritel besar terpilih yang ada di Kota Madiun sebagai variabel dependent (Y) dapat dilihat pada tabel berikut:

Tabel 8. Hasil Analisis Regresi

Coefficients $^{\mathrm{a}}$

\begin{tabular}{|ll|r|r|}
\hline \multirow{2}{*}{ Model } & \multicolumn{2}{|c|}{ Unstandardized Coefficients } \\
\cline { 3 - 4 } & \multicolumn{1}{|c|}{ B } & Std. Error \\
\hline 1 & (Constant) & 1.734 & .518 \\
& Store Atmosphere & .197 & .098 \\
& Hedonic Shopping & .164 & .079 \\
& Promosi & .240 & .073 \\
\hline
\end{tabular}

a. Dependent Variable: Impulsive Buying

Sumber: Output SPSS, Regression

Dari hasil uji regresi pada Tabel 8 dapat diformulasikan persamaan regresi linier berganda sebagai berikut:

$\mathrm{Y}=\mathrm{a}+\mathrm{b}_{1} \mathrm{X}_{1}+\mathrm{b}_{2} \mathrm{X}_{2}+\mathrm{b}_{3} \mathrm{X}_{3}$

$=1,734+0,197 X_{1}+0,164 X_{2}+0,240 X_{3}$

Interpretasi dari persamaan regresi linier berganda di atas adalah sebagai berikut:

a. Nilai konstanta sebesar 1,734; menunjukkan bahwa impulsive buying pada konsumen berbagai ritel besar terpilih yang ada di Kota Madiun adalah sebesar 1,734, dengan asumsi variabel store atmosphere, hedonic shopping, dan promosi sama dengan nol atau tidak ada.

b. Variabel store atmosphere $\left(\mathrm{X}_{1}\right)$ yang bernilai sebesar 0,197 (positif) menunjukkan adanya pengaruh positif variabel store atmosphere terhadap impulsive buying pada konsumen berbagai ritel besar terpilih yang ada di Kota Madiun. Jika store atmosphere $\left(\mathrm{X}_{1}\right)$ meningkat sebesar 1, maka impulsive buying konsumen juga akan meningkat sebesar 0,197.

c. Variabel hedonic shopping $\left(\mathrm{X}_{2}\right)$ yang bernilai sebesar 0,164 (positif) menunjukkan adanya pengaruh positif hedonic shopping terhadap impulsive buying konsumen berbagai ritel besar terpilih yang ada di Kota Madiun. Jika hedonic shopping $\left(\mathrm{X}_{2}\right)$ meningkat sebesar 1, maka impulsive buying konsumen juga akan meningkat sebesar 0,164.

d. Variabel promosi $\left(\mathrm{X}_{3}\right)$ yang bernilai sebesar 0,240 (positif) menunjukkan adanya pengaruh positif variabel promosi terhadap impulsive buying konsumen berbagai ritel besar terpilih yang ada di Kota Madiun. Jika promosi $\left(\mathrm{X}_{3}\right)$ meningkat sebesar 1 , maka impulsive buying konsumen juga akan meningkat sebesar 0,240.

Analisis Koefisien Determinasi

Berdasarkan hasil uji koefisien determinasi $\left(\mathrm{R}^{2}\right)$ menggunakan program SPSS diperoleh hasil sebagai berikut: 
Website : http://ekomaks.unmermadiun.ac.id/index.php/ekomaks

Tabel 9. Hasil Analisis Koefisien Determinasi $\left(\mathrm{R}^{2}\right)$

Model Summary

\begin{tabular}{|l|l|l|r|r|}
\hline Model & $\mathrm{R}$ & R Square & $\begin{array}{c}\text { Adjusted R } \\
\text { Square }\end{array}$ & $\begin{array}{c}\text { Std. Error of } \\
\text { the Estimate }\end{array}$ \\
\hline 1 & $.442^{\mathrm{a}}$ & .196 & .171 & .2864 \\
\hline
\end{tabular}

a. Predictors: (Constant), Promosi, Store Atmosphere, Hedonic Shopping

Sumber: Output SPSS, Regression

Berdasarkan Tabel 9, diketahui besarnya $R$ Square $\left(\mathrm{R}^{2}\right)$ adalah 0,196 atau 19,6\% yang berarti 19,6\% impulsive buying pada konsumen berbagai ritel besar terpilih yang ada di Kota Madiun dapat dijelaskan oleh variabel store atmosphere, hedonic shopping, dan promosi, sedangkan sisanya, yaitu sebesar $80,4 \%$ dijelaskan oleh variabel-variabel yang tidak dimasukkan dalam model penelitian ini.

Uji Hipotesis

Uji t (Uji Parsial)

Uji t digunakan untuk menguji signifikansi pengaruh masing-masing variabel bebas terhadap variabel terikat.

Pengujian terhadap variabel store atmosphere $(X 1)$

Nilai $\mathrm{t}_{\text {hitung }}$ variabel store atmosphere $\left(\mathrm{X}_{1}\right)$ sebesar 2,017 lebih besar dari $\mathrm{t}_{\text {tabel }}(1,98498)$ dan $p$-value $(0,046)$ lebih kecil dari $\alpha$ $(0,05)$, maka $\mathrm{H}_{\mathrm{o}}$ ditolak dan $\mathrm{H}_{\mathrm{a}}$ diterima. Dengan demikian hipotesis penelitian yang menyatakan "Store atmosphere secara parsial berpengaruh terhadap impulsive buying yang dilakukan masyarakat di ritel-ritel modern yang ada di Kota Madiun", diterima kebenarannya.

Pengujian terhadap variabel hedonic shopping (X2)

Nilai $\mathrm{t}_{\text {hitung }}$ variabel hedonic shopping $\left(\mathrm{X}_{2}\right)$ sebesar 2,077 lebih besar dari $\mathrm{t}_{\text {tabel }}(1,98498)$ dan $p$-value $(0,041)$ lebih kecil dari $\alpha$ $(0,05)$, maka $\mathrm{H}_{\mathrm{o}}$ ditolak dan $\mathrm{H}_{\mathrm{a}}$ diterima. Dengan demikian hipotesis penelitian yang menyatakan "Hedonic shopping secara parsial berpengaruh terhadap impulsive buying yang dilakukan masyarakat di ritel-ritel modern yang ada di Kota Madiun" terbukti kebenarannya.

\section{Pengujian terhadap variabel promosi $(X 3)$}

Nilai $t_{\text {hitung }}$ variabel promosi $\left(\mathrm{X}_{3}\right)$ sebesar 3,283 lebih besar dari $\mathrm{t}_{\text {tabel }}(1,98498)$ dan $p$-value $(0,001)$ lebih kecil dari $\alpha(0,05)$, maka $\mathrm{H}_{\mathrm{o}}$ ditolak dan $\mathrm{H}_{\mathrm{a}}$ diterima. Dengan demikian hipotesis penelitian yang menyatakan "Promosi secara parsial berpengaruh terhadap impulsive buying yang dilakukan masyarakat di ritel-ritel modern yang ada di Kota Madiun” terbukti kebenarannya.

\section{Uji F (Uji Simultan)}

Analisis uji $\mathrm{F}$ digunakan untuk mengetahui pengaruh dari seluruh variabel independent, yaitu store atmosphere $\left(\mathrm{X}_{1}\right)$, hedonic shopping $\left(\mathrm{X}_{2}\right)$, dan promosi $\left(\mathrm{X}_{3}\right)$ secara bersama-sama terhadap variabel dependent (impulsive buying yang dilakukan konsumen berbagai ritel besar terpilih yang ada di Kota Madiun). Melalui penghitungan data dengan program SPSS, dapat diketahui nilai $\mathrm{F}_{\text {hitung }}$ seperti dalam tabel sebagai berikut:

\begin{tabular}{|c|c|c|c|c|c|c|}
\hline \multirow[b]{2}{*}{ Model } & & \multicolumn{2}{|c|}{ Unstandardized Coefficients } & \multirow{2}{*}{$\begin{array}{c}\begin{array}{c}\text { Standardized } \\
\text { Coefficients }\end{array} \\
\text { Beta }\end{array}$} & \multirow[b]{2}{*}{$t$} & \multirow[b]{2}{*}{ Sig. } \\
\hline & & B & Std. Error & & & \\
\hline \multirow[t]{4}{*}{1} & (Constant) & 1.734 & .518 & & 3.347 & .001 \\
\hline & Store Atmosphere & .197 & .098 & 198 & 2.017 & .046 \\
\hline & Hedonic Shopping & .164 & .079 & .204 & 2.077 & .041 \\
\hline & Promosi & .240 & .073 & .301 & 3.283 & .001 \\
\hline
\end{tabular}

Sumber: Hasil Olah Data SPSS, Regression

Kriteria pengujian yang digunakan adalah dengan menentukan nilai $\mathrm{F}_{\text {tabel }}$ terlebih dahulu. Nilai $\mathrm{F}_{\text {tabel }}$ diperoleh melalui penentuan nilai level of significant $(\alpha)$ serta $d f$ pembilang $\left(d f_{1}\right)$ dan $d f$ penyebut $\left(d f_{2}\right)$. Dalam penelitian ini, dipilih level of significant $(\alpha)=0,05(5 \%), d f_{1}=\mathrm{k}-1$, dan $d f_{2}=\mathrm{n}-\mathrm{k}$, dimana $\mathrm{n}=$ banyaknya sampel dan $\mathrm{k}=$ banyaknya variabel bebas dan terikat. Jumlah sampel yang digunakan dalam penelitian adalah 100 orang responden. Banyaknya variabel bebas dan terikat $=4$, yaitu store atmosphere $\left(\mathrm{X}_{1}\right)$, hedonic shopping $\left(\mathrm{X}_{2}\right)$, promosi $\left(\mathrm{X}_{3}\right)$, dan impulsive buying $(\mathrm{Y})$. Dengan demikian diperoleh nilai $d f_{1}=\mathrm{k}-1=4-1=3$ dan $d f_{2}=100-4=96$. Pada tabel $\mathrm{F}_{0,05}, d f(3)(96)$ diperoleh nilai $\mathrm{F}_{\text {tabel }}=2,70$. Dari hasil perhitungan, diperoleh nilai $\mathrm{F}_{\text {hitung }}$ sebesar 7,787. Dari angka tersebut berarti $\mathrm{F}_{\text {hitung }}(7,787)$ lebih besar dari $\mathrm{F}_{\text {tabel }}(2,70)$ dan nilai $p$-value $=$ 0,000 lebih kecil dari level of significant $(\alpha=0,05)$, maka $\mathrm{H}_{\mathrm{o}}$ ditolak dan $\mathrm{H}_{\mathrm{a}}$ diterima. Hal ini berarti terdapat pengaruh yang signifikan antara store atmosphere, hedonic shopping, dan promosi terhadap impulsive buying yang dilakukan konsumen berbagai ritel besar terpilih yang ada di Kota Madiun. Dengan demikian hipotesis penelitian yang menyatakan "Store atmosphere, hedonic shopping, dan promosi secara simultan berpengaruh terhadap impulsive buying yang dilakukan masyarakat di ritel-ritel modern yang ada di Kota Madiun" terbukti kebenarannya.

Untuk menjawab rumusan masalah yang diuraikan pada latar belakang, terdapat 4 hipotesa. Hasil pengujian hipotesis 1 menunjukkan bahwa hipotesis pertama diterima. Variabel store atmosphere secara parsial berpengaruh terhadap impulsive buying yang dilakukan masyarakat di ritel-ritel modern yang ada di Kota Madiun dengan nilai signifikan yang lebih kecil dari 0,05 yaitu 0,046 dan nilai $t_{\text {hitung }}(2,017)>t_{\text {tabel }}(1,98498)$. Hasil uji regresi linear menunjukkan nilai konstanta 0,197 (positif). Jadi, dapat disimpulkan bahwa store atmosphere berpengaruh positif dan signifikan terhadap impulsive buying. Jika store 
atmosphere konsumen berbagai ritel besar terpilih yang ada di Kota Madiun meningkat, maka impulsive buying konsumen juga akan meningkat. Hasil penelitian ini mendukung temuan penelitian yang dilakukan Leba dan Suhermin (2015) serta Pamayun dan Ekawati (2016: 4156) yang menemukan bahwa atmosfer gerai atau store atmosphere berpengaruh positif dan signifikan terhadap pembelian impulsif.

Store atmosphere yang dirasakan oleh pelanggan sangat mempengaruhi emosi mereka dalam berbelanja sehingga pelanggan menjadi nyaman dan dapat berlama-lama di dalam toko. Hal ini seperti yang disampaikan Berman dan Evans (dalam Agusta, 2013: 30) bahwa ada banyak hal yang mempengaruhi persepsi konsumen pada toko, diantaranya: aroma dan musik, warna dan pencahayaan, serta kebersihan. Ketika pelanggan merasakan suasana yang baik, maka secara tidak langsung emosi positif yang dimiliki pengunjung juga ikut meningkat. sehingga mengakibatkan pengunjung merasa senang dan ingin berbelanja yang di luar daftar keperluannya. Impulsive buying muncul dapat disebabkan dari hasil rangsangan suasana toko yang mendukung sehingga terjadinya keputusan pembelian yang tidak direncanakan tersebut.

Mengacu pada hasil jawaban kuesioner yang disampaikan responden, diketahui bahwa responden beranggapan bahwa ritel modern yang dikunjunginya memiliki aroma yang harum sehingga membuat nyaman pengunjung, memiliki penerangan yang cukup serta menggunakan lampu dengan cahaya tidak menyilaukan mata, serta musik yang dimainkan pihak toko membuat saya merasa nyaman berbelanja di dalamnya. Pengaturan manekin untuk memajang pakaian juga membuat pengujung tertarik dan disertai dengan info tentang harga yang jelas.

Store atmosphere yang disesuaikan dengan karateristik pribadi seseorang akan menciptakan pengaruh yang berbeda-beda. Semakin baik pengelolaan store atmosphere, maka akan semakin menarik konsumen untuk melakukan pembelian pada toko tersebut. Apabila pelanggan merasa nyaman dengan lingkungan toko, akan meningkatkan impulsive buying.

Hasil pengujian hipotesis 2 menunjukkan bahwa hipotesis kedua diterima. Variabel hedonic shopping secara parsial berpengaruh terhadap impulsive buying yang dilakukan masyarakat di ritel-ritel modern yang ada di Kota Madiun dengan nilai signifikan yang lebih kecil dari 0,05 yaitu 0,041 dan nilai $t_{\text {hitung }}(2,077)>t_{\text {tabel }}(1,98498)$. Hasil uji regresi linear menunjukkan nilai konstanta 0,164 (positif). Jadi, dapat disimpulkan bahwa hedonic shopping berpengaruh positif dan signifikan terhadap impulsive buying. Jika hedonic shopping yang dilakukan masyarakat di ritel-ritel modern yang ada di Kota Madiun meningkat, maka impulsive buying konsumen juga akan meningkat. Hasil penelitian ini mendukung penelitian yang dilakukan Foroughi, dkk. (2013: 760) yang menemukan bahwa ada hubungan positif dan langsung antara nilai belanja hedonik dengan impulse buying. Pada penelitian yang dilakukan oleh Kosyu, dkk. (2014: 7) juga ditemukan bahwa hedonic shopping motives berpengaruh signifikan terhadap impulse buying.

Menurut Usvita (2016: 71-75), hedonic shopping value memainkan peran penting dalam impulse buying. Oleh karena itu, seringkali konsumen mengalami impulse buying ketika didorong oleh keinginan hedonis atau sebab lain di luar alasan ekonomi, seperti karena rasa suka terhadap produk, senang, sosial, atau pengaruh emosional. Hedonic shopping mengacu pada rasa kenikmatan dan kesenangan yang konsumen terima dari seluruh pengalaman membeli yang terkait dengan kegiatan berbelanja. Konsumen yang memiliki gaya hidup hedonis tinggi akan cenderung melakukan pembelian impulsif terhadap produk-produk di luar kebutuhannya.

Mengacu pada jawaban kuesioner yang disampaikan responden, diketahui bahwa konsumen mereasa senang jika dapat membeli barang yang orang lain belum memilikinya, konsumen merasa bahwa berbelanja adalah kegiatan yang menyenangkan, serta saat ada model pakaian yang sedang trend, konsumen segera membelinya.

Adanya rasa kenikmatan dan kesenangan konsumen pada saat berbelanja akan menimbulkan impulse buying. Konsumen akan berbelanja secara tiba-tiba dan tidak terencana dalam berbelanja. Jadi, hedonic shopping berpengaruh terhadap impulse buying.

Hasil pengujian hipotesis 3 menunjukkan bahwa hipotesis ketiga diterima. Variabel promosi secara parsial berpengaruh terhadap impulsive buying yang dilakukan masyarakat di ritel-ritel modern yang ada di Kota Madiun dengan nilai signifikan yang lebih kecil dari 0,05 yaitu 0,001 dan nilai $t_{\text {hitung }}(3,283)<t_{\text {tabel }}(1,98498)$. Hasil uji regresi linear menunjukkan nilai konstanta 0,240 (positif). Jadi, dapat disimpulkan bahwa promosi berpengaruh positif dan signifikan terhadap impulsive buying. Jika promosi yang disampaikan para peritel modern meningkat, maka impulsive buying yang dilakukan konsumen pada berbagai ritel besar terpilih yang ada di Kota Madiun juga akan meningkat. Hasil penelitian ini mendukung penelitian yang dilakukan Leba dan Suhermin (2015: 13) yang menemukan bahwa variabel promosi memiliki pengaruh positif dan signifikan terhadap variabel pembelian impulsif. Hal ini menunjukkan semakin baik kegiatan promosi yang dilakukan maka akan meningkatkan pembelian impulsif pada konsumen.

Salah satu strategi yang dilakukan peritel untuk meningkatkan penjualan adalah dengan melakukan strategi promosi. Menurut Herlambang (2014: 41) promosi merupakan "salah satu cara untuk menginformasikan, membujuk, dan mengingatkan konsumen secara langsung maupun tidak langsung tentang suatu produk atau brand yang dijual." Kegiatan promosi di dalam toko dapat menjadi salah satu alternatif untuk menyentuh atau mempengaruhi emosi konsumen, terutama dalam keputusan pembelian impulsif.

Berdasarkan jawaban kuesioner yang disampaikan responden, diketahui bahwa saat mengunjungi ritel modern tanpa ada niat untuk berbelanja, konsumen mendapat informasi tentang diskon yang ditawarkan serta informasi tentang produk oleh karyawan toko dengan jelas, maka konsumen tertarik untuk membeli barang tersebut. Selain itu, saat mengetahui ada diskon harga yang besar serta adanya keinginan untuk mendapatkan bonus sebagai member, maka konsumen yang sebelumnya tidak meminiliki niat untuk berbelanja, akan melakukan pembelian sebagai bentuk dari perilaku impulsive buying. Berdasarkan hal tersebut, 


\section{Website : http://ekomaks.unmermadiun.ac.id/index.php/ekomaks}

maka kegiatan promosi berpengaruh terhadap impulsive buying yang dilakukan konsumen pada ritel-ritel modern di Kota Madiun.

Hasil pengujian hipotesis 4 menunjukkan bahwa hipotesis keempat diterima. Variabel store atmosphere, hedonic shopping, dan promosi berpengaruh terhadap impulsive buying konsumen berbagai ritel besar terpilih yang ada di Kota Madiun dengan nilai signifikan 0,000 dan nilai $\mathrm{F}_{\text {hitung }}(7,787)>\mathrm{F}_{\text {tabel }}(2,70)$. Jadi, dapat disimpulkan bahwa store atmosphere, hedonic shopping, dan promosi secara simultan berpengaruh terhadap impulsive buying konsumen.

Impulsive buying atau pembelian impulsif merupakan sebuah fenomena dan kecenderungan perilaku berbelanja meluas yang terjadi di dalam pasar sehingga menjadi poin penting dalam pemasaran. Seringkali keputusan pembelian diambil oleh konsumen merupakan pembelian tanpa rencana sebelumnya, dimana pembelian tersebut dilakukan secara spontan, karena konsumen tertarik dengan adanya diskon, suasana hati yang positif maupun karena adanya stimulus dari lingkungan toko yang menarik, sehingga menimbulkan minat konsumen untuk membeli.

\section{IV.KESIMPULAN}

Berdasarkan hasil analisis dan pembahasan tentang pengaruh store atmosphere, hedonic shopping, dan promosi terhadap impulsive buying yang dilakukan masyarakat di ritel-ritel modern yang ada di Kota Madiun, maka kesimpulan sebagai berikut:

1. Store atmosphere secara parsial berpengaruh terhadap impulsive buying yang dilakukan masyarakat di ritel-ritel modern yang ada di Kota Madiun.

2. Hedonic shopping secara parsial berpengaruh terhadap impulsive buying yang dilakukan masyarakat di ritel-ritel modern yang ada di Kota Madiun.

3. Promosi secara parsial berpengaruh terhadap impulsive buying yang dilakukan masyarakat di ritel-ritel modern yang ada di Kota Madiun.

4. Store atmosphere, hedonic shopping, dan promosi secara simultan berpengaruh terhadap impulsive buying yang dilakukan masyarakat di ritel-ritel modern yang ada di Kota Madiun.

\section{UCAPAN TERIMAKASIH}

Terimakasih pada Universitas Merdeka Madiun atas bantuan dana penelitian yang diberikan sehingga penelitian ini dapat dilaksanakan.

\section{VI.DAFTAR PUSTAKA}

Abdolvand, Mohamad Ali., Hanzaee, Kambiz Heidarzadeh., Rahnama, Afshin., dan Khospanjeh. 2011. The Effect of Situasional and Individual Factors on Impulse Buying. World Applied Sciences Journal. Vol. 13. No. 9. pp. 2108-2117.

Agusta, Rifki Arga. 2013. Pengaruh Store Atmosphere dan Word of Mouth terhadap Minat Beli Konsumen (Studi pada Konsumen The House of Raminten Yogyakarta. Skripsi. Tidak Dipublikasikan. Yogyakarta: Universitas Negeri Yogyakarta.

Fahd, Faishal dan Sugiarto, Yohanes. 2015. Analisis Pengaruh Promosi dan Atmosfer Gerai Terhadap Impulse Buying Melalui Emosi Positif Sebagai Variabel Intervening. Diponegoro Journal of Management. Vol. 4. No. 2. hal. 1-8.

Foroughi, Amir., Buang, Nor Aishah., Senik, Zizah Che., dan Hajmisadeghi, Reihanehsadat. 2013. Impulse Buying Behaviour and Moderating Role of Gender among Iranian Shoppers. Journal of Basic and Applied Scientific Research. Vol. 3. No. 4. hal. 760-769.

Herlambang, Susatyo. 2014. Basic Marketing (Dasar-Dasar Pemasaran). Yogyakarta: Gosyen Publishing.

Irani, Neda. 2011. The Effects of Variety-seeking Buying Tendency and Price Sensitivity on Utilitarian and Hedonic Value in Apparel Shopping Satisfaction. International Journal of Marketing Studies. Vol. 3. No. 1. hal. 89-103.

Japarianto, Edwin. 2010. Analisa Faktor Type Hedonic Shopping Motivation dan Faktor Pembentuk Kepuasan Tourist Shopper di Surabaya. Jurnal Manajemen dan Kewirausahaan. Vol. 12. No. 1. hal. 76-85.

Leba, Elizabet dan Suhermin. 2015. Pengaruh Atmosfer Gerai dan Promosi Terhadap Pembelian Impulsif yang Dimediasi Emosi Positif. Jurnal Ilmu dan Riset Manajemen. Vol. 4. No. 1. hal. 1-17.

Mowen. J. C. dan Minor. 2010. Consumer behavior. Boston: USA Irwin: Mc Graw Hill.

Pamayun, Tjokorda Istri Dwi Pradnyawati dan Ekawati, Ni Wayan. 2016. Pengaruh Promosi, Atmosfer Gerai, dan Merchandise Terhadap Pembelian Impulsif Pada Hardy's Mall Gatsu Denpasar. E-Jurnal Manajemen Unud. Vol. 5. No. 7. hal. 4132-4160.

Peter, J. P. dan Olson, dan J. C. 2014. Perilaku Konsumen dan Strategi Pemasaran. Edisi 9. Jakarta: Salemba Empat.

Prastia, F. E. 2013. Pengaruh Shopping Lifestyle, Fashion Involvement dan Hedonic Shopping Value Terhadap Impulse Buying Behaviour Pelanggan Toko Elizabeth Surabaya. Jurnal Ilmiah Mahasiswa Manajemen. Vol. 1. No. 2. hal. 1-10.

Purwanto. 2007. Instrumen Penelitian Sosial dan Pendidikan. Yogyakarta: Pustaka Pelajar.

Sari, Aprilia Eka. 2014. Analisis Faktor yang Mempengaruhi Pembelian Spontan Jurnal Sains Pemasaran Indonesia. Volume XIII. No. 1. hal. 55-73.

Smith, Aaron C. T. 2008. Introduction to Sport Marketing. Journal. Oxford: Elsefier Ltd.

Subagio, H. 2011. Pengaruh Atribut Supermarket terhadap Motif Belanja Hedonik Motif Belanja Utilitarian dan Loyalitas Konsumen. Jurnal Manajemen Pemasaran. Vol. 6. No. 1. hal. 8-21.

Sugiyono. 2015. Metode Penelitian: Pendekatan Kuantitatif, Kualitatif, dan R\&D. Bandung: Alfabeta.

Tjiptono, Fandy. 2008. Strategi Pemasaran. Edisi 3. Yogyakarta: Andi Offset.

Umar, Husein. 2011. Metode Penelitian untuk Skripsi dan Tesis Bisnis. Jakarta: Raja Grafindo Persada.

Usvita, Mega. 2016. Pengaruh Hedonic Shopping Value, Shopping Lifestyle Dan Positive Emotion Terhadap Impulse Buying Pada Plaza Andalas Padang. eJurnal Apresiasi Ekonomi. Vol. 4. No. 1. hal. 71-75.

Utami, Christina Widya. 2010. Manajemen Ritel. Edisi 2. Jakarta: Salemba Empat.

Yistiani, Ni Nyoman Manik., Yasa, Ni Nyoman Kerti., dan Suasana, I.G.A Ketut Gede. 2012. Pengaruh Atmosfer Gerai dan Pelayanan Ritel Terhadap Nilai Hedonik dan Pembelian Impulsif Pelanggan Matahari Department Store Duta Plaza di Denpasar. Jurnal Manajemen, Strategi Bisnis, dan Kewirausahaan. Vol. 6. No. 2. hal. 139-148. 